BАTОВОН

Jurnal Pengabdian Pada Masyarakat

Available online at:https://journal.isi-padangpanjang.ac.id/index.php/Batoboh

\title{
PEMBINAAN ADMINISTRASI DENGAN MEMANFAATKAN SOFTWARE APPLICATION
}

\author{
Sunarsan Sitohang \\ Cecep Endang
}

\author{
Teknik Informatika, Teknik dan Komputer, Universitas Putera Batam \\ Jl. R. Soeprapto, Muka Kuning, Kota Batam, Kepulauan Riau 29452 \\ Sunarsan@puterabatam.ac.id \\ cep43end@gmail.com
}

\begin{abstract}
ABSTRAK
Jaman digitalisasi dan teknologi maju saat ini sangat membantu manusia dalam mengerjakan pekerjaannya, sehingga harus diterapkan untuk mendapat manfaatnya. Tidak dapat dipungkiri masih banyak masyarakat sangat enggan dengan penggunaan teknologi. Keengganan ini bisa diakibatkan karena tidak adanya kemauan belajar ataupun fasilitas yang kurang memadai serta tidak adanya yang memotivasi atau pembinaan. Pembentukan RT 13 dan Pembinaan Kesejahteraan Keluarga (PKK) di Perumahan Taman Cipta Asri Tahap III masih baru sehingga beberapa pengurusnya masih tabu dengan software aplikasi untuk mengelola administrasi PKK. Pembinaan pemanfaatan software aplikasi untuk administrasi ini bertujuan agar pengurus organisasi PKK Perumahan Taman Cipta Asri Tahap 3 RT 13 RW 12 Kota Batam bisa memahami bagaimana memanfaatkan software aplikasi untuk membantu kegiatan PPK, cara penggunaan software aplikasi untuk kegiatan PPK baik berupa pembuatan laporan keuangan yang baik, presentasi yang menarik, surat undangan yang baik dan lain sebagainya. Oleh karena itu, pembinaan software aplikasi ini akan sangat dibutuhkan bagi pengurus Organisasi PKK yang berminat untuk mempelajarinya. Pembinaan dilaksanakan dengan metode memberikan materi tutorial, mempraktekkannya dengan pendampingan dan evaluasi. Target utama pembinaan ini adalah menciptakan masyarakat yang dapat menerapkan teknologi khususnya software aplikasi untuk mempermudah mengerjakan pekerjaannya, khususnya dalam administrasi PKK dengan memanfaatkan software aplikasi serta memahami bagaimana penggunaan Software aplikasi tersebut
\end{abstract}

Kata Kunci: Administrasi; Software Aplikasi; PKK 


\section{Jurnal Batoboh, Vol 5 , No 2, Oktober 2020}

Sunarsan Sitohang, Cecep Endang

\section{PENDAHULUAN}

Salah satu perkembangan teknologi saat ini yaitu dibidang komputer, komputer saat ini dikembangkan untuk banyak hal. Program aplikasi merupakan salah satu pengembangan dalam teknologi komputer. Sangat banyak sekali aplikasi yang dibuat baik perorangan, perusahaan maupun korporasi dengan tujuan yang beragam. Pada intinya tujuan dari program aplikasi tersebut secara umum adalah mempermudah pekerjaan manusia. Kebutuhan program aplikasi di zaman yang serba canggih seperti sekarang ini tentunya akan menjadi sangat penting sama halnya seperti kebutuhan sehari-hari.

Jenis dan kapasitas program aplikasi yang diperlukan pun tentu akan beragam untuk menyelesaikan suatu masalah. Tidak sedikit orang menggunakan program aplikasi sebagai alat bantu untuk mengerjakan pekerjaannya. Pengaplikasian tersebut dapat dilakukan dengan berbagai cara diantaranya adalah dengan melalui komputer sebagai media atau alat penyampaian informasi. Contohnya Aplikasi Microsoft Excel dimanfaatkan dalam pelatihan dasar-dasar statistika (Dhewy 2018). Sistem aplikasi komputer dimanfaatkan dalam tata kelola administrasi desa (Basir et al. 2020). Ilmu teknologi computer dipelajari untuk meningkatkan administrasi desa. ( et al. 2020). Dengan sistem terkomputerisasi yang bertujuan untuk meningkatkan mutu dan kualitas suatu aplikasi, diharapkan hasilnya akan memberikan solusi serta mengambil keputusan dengan tepat. (Rosa \& Shalahuddin, 2011)

Berdasarkan hal diatas, di negara Indonesia ini terdapat begitu banyak jenis pekerjaan, ORMAS, bidang usaha, perusahaan, instansi, departemen baik yang bersifat milik negara ataupun swasta. Dalam suatu perusahaan atau instansi tentunya terdapat karyawan, pengurus atau pegawai guna memajukan dan menggerakkan perusahaan tersebut dengan adanya pemanfaatan teknologi informasi.

Perumahan Cipta Asri tahap 3 RT 13 RW 12 merupakan perumahan baru. Situasi yang kami lihat dilapangan menunjukkan bahwa masih ada beberapa pengurus organisasi PKK yang belum paham bagaimana pemanfaatan program aplikasi komputer serta kurang memahami bagaimana menggunakan komputer untuk administrasi, khususnya administrasi PKK. Pengusul melihat bahwa pembuatan laporan-laporan dan dokumen-dokumen 


\section{Jurnal Batoboh, Vol 5 , No 2, Oktober 2020}

Sunarsan Sitohang, Cecep Endang

masih kurang rapi dan masih semi komputerisasi.

Sofware aplikasi yang dimaksud adalah miscrosoft office yang terdiri dari microsoft word, microsoft excel dan microsoft power point. Microsoft word adalah applikasi pengolah kata, excel adalah sebuah program aplikasi lembar kerja spreadsheet yang dibuat dan didistribusikan oleh Microsoft Corporation yang dapat dijalankan pada Microsoft Windows dan Mac OS dan powerpoint adalah sebuah program untuk presentasi (Jarot S., Shenia A. 2012)

\section{Permasalahan}

Adapun permasalahan yang temui adalah PKK masih baru sehingga masih ada beberapa pengurus organisasi PKK yang belum mengetahui cara untuk memanfaatkan aplikasi komputer yaitu microsoft word, microsoft excel dan microsoft power point untuk administrasi PKK. Mereka masih kurang memahami secara penuh bagaimana cara penggunaan program aplikasi komputer untuk dokumentasi PKK, yang mereka ketahui hanya cara menjalankannya yang sederhana saja. Mereka tidak memahami pemanfaatan aplikasi software tersebut. Contohnya penggunaan rumus dalam excel masih belum secara otomatis sehingga kemungkinan akan terjadi kesalahan dalam pelaporan keuangan dan lain sebagainya.

Untuk saat ini pengurus PKK secara Hal 80 organisasi masih belum tersusun sempurna, mengingat RT 13 masih baru dibentuk. Berdasarkan hasil wawancara kami dengan ketua RT 13 dan istrinya selaku ketua PKK, untuk anggota pengurusan PKK yang ada saat ini terdiri dari 5 orang dan akan bertambah seiring waktu berjalan. sehingga akan mempengaruhi jumlah peserta pada pembinaan ini,

\section{Metode Pelaksanaan}

Metode yang dilaksanakan oleh pengabdi adalah memberikan materi dan praktek langsung tentang bagaimana memanfaatkan software aplikasi untuk administrasi PKK. Dalam pelaksanaan setiap peserta akan mendapatkan salinan materi yaitu berupa tutorial yang telah disiapkan sesuai dengan kebutuhan pengurus PKK (Simanjuntak and Handoko 2019). Adapun rincian pelaksanaannya adalah sebagai berikut:

\section{Ketua pengabdi}

1. Menyampaikan kata pembukaan, pengenalan software aplication manfaat dan keguanaannya khususnya miscrosoft power point dan word 
2. Meyampaikan materi miscrosoft power point: langkah-langkah menjalankan, membuat presentasi, memasukkan backgraund dll.

3. Meyampaikan materi miscrosoft word: cara memulai dan mengelola microsoft word dll.

\section{Anggota pengabdi}

1. Pengenalan miscrosoft excel, manfaat dan kegunaannya.

2. Meyampaikan materi miscrosoft power excel: langkah-langkah menjalankan, mengenal fungsi dan rumus dalam excel

3. Menangani pelaksanaan praktek

\section{Evaluasi Pelaksanaan Kegiatan}

Evaluasi yang pengabdi lakukan adalah dengan memantau secara langsung pelatihan yang diselenggarakan, apakah peserta dapat mengikuti pelatihan dengan baik atau penyampaian materi atau prakteknya terlalu cepat atau tidak. Kemudian nantinya akan diuji peserta pelatihan dengam menggunakan software aplikasi tersebut, pengujiannya berupa pemberian latihan yang relevan dengan materi pelatihan yang diberikan.

\section{Keberlanjutan Kegiatan}

Pembinaan yang akan dilakukan oleh pengabdi akan dilanjutkan dengan memonitor peserta dan membantu mengembangkan kemampuannya dalam penggunaan software aplikasi sampai dengan mahirnya untuk administrasi organisasi PKK. Jika kedepannya peserta pengabdian mengalami kendala, tim pengabdi siap untuk membantu dan membina kembali.

\section{PEMBAHASAN}

Hasil dari kegiatan ini adalah para pengurus organisasi Pembinaan Kesejahteraan Keluarga (PKK) paham bagaimana memanfaatkan Software Aplication dan komputer untuk administrasi. Susunan pelaksanaan dan pemateri yang terlibat dalam pembinaan administrasi dengan memanfaatkan software aplication seperti pada table $1 \mathrm{di}$ bawah ini.

\section{Hal 81}


Tabel 1 Susunan Pelaksanaan Kegiatan

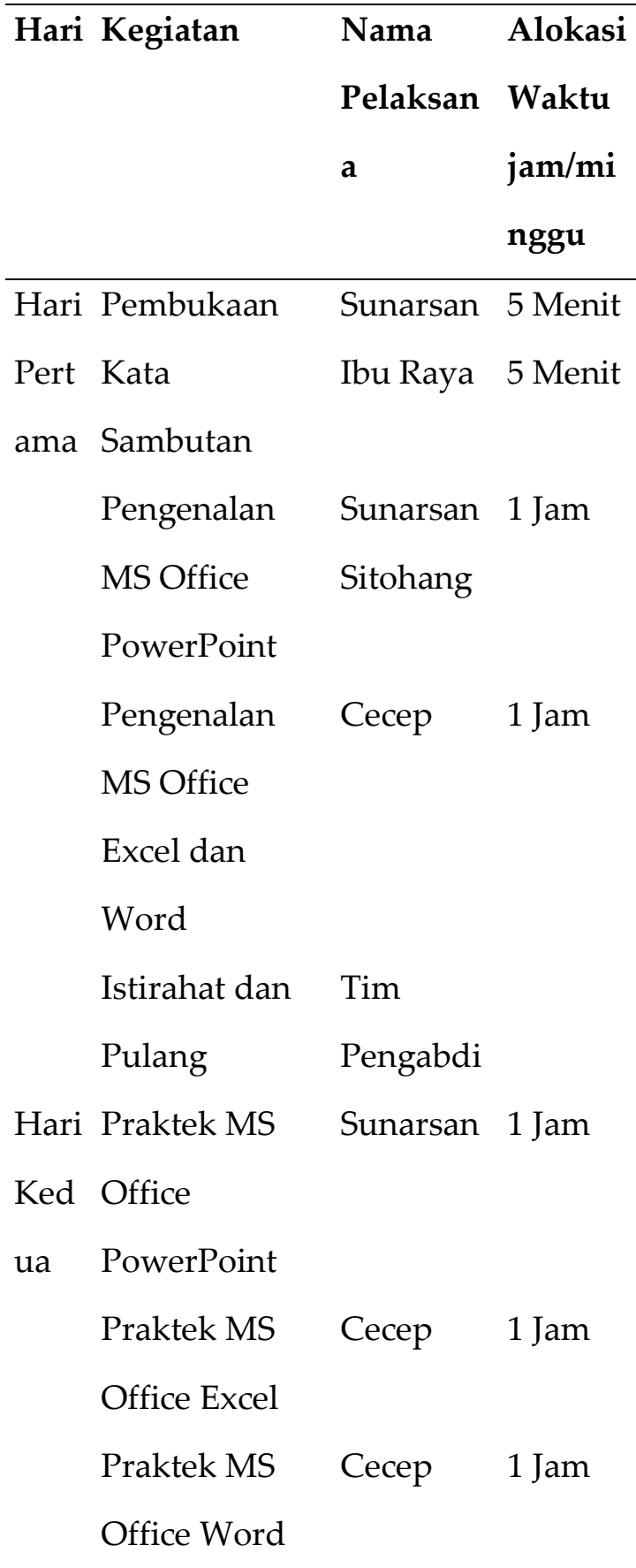

$\overline{\text { Berikut uraian-uraian yang dilatih dengan }}$

Ms word.

1. Membuat surat

2. Membuat tabel
3. Membuat tulisan dengan berbagai variasi (word art)

4. Memasukan gambar

5. dan membuat dokumen lainnya

Untuk Ms excel sebagai berikut:

1. Membuat tabel, mengurutkan data

2. Menjumlah sub total dan grand total

3. Mengedit teks secara langsung di sel

4. Menjumlah secara otomatis dengan autosum

5. Membuat grafik secara cepat dan mudah dengan fungsi chard wizard

6. Mencetak dengan proporsi bebas.

Aplikasi PowerPoint digunakan untuk membuat suatu presentasi, aplikasi ini bisa dijalankan dengan mudah dan dapat dikreasikan dengan berbagai animasi yang menarik baik dalam pemberian warna, gambar, suara maupun visual lainnya dalam waktu yang relatif singkat. PowerPoint pada Microsot Office ini sering digunakan untuk presentasi pendidik, pelajar, trainer, marketing ataupun manager perusahaan. Microsoft PowerPoint ini juga dapat digunakan oleh siapa saja yang akan mengadakan presentasi atau orasi, karena pada prinsipnya slide-slide yang akan ditampilkan nantinya merupakan alat bantu dalam melakukan presentasi agar tidak menyimpang dari konsep awal atau konsep utama 
pembicaraan. Karena kadang kala presenter seakan terbawa arus pembicaraan dalam melaksanakan presentasi sehingga tanpa disadarinya pembicaraan atau materi yang dipaparkannya sudah keluar dari jalur konsep yang seharusnya dibahas atau disampaikan dan membuat waktu terbuang percuma.

Penjabaran kegiatan yang diberikan dalam kegiatan pembinaan ini adalah sebagai berikut:

1. Menjelaskan, memaparkan dan memperkenalkan manfaat dan penggunaan teknologi informasi dalam membantu para pengurus Pembinaan Kesejahteraan Keluarga (PKK). Membantu para pengurus Pembinaan Kesejahteraan Keluarga (PKK) dalam mempersiapkan, membuat, menyusun, menyelesaikan pekerjaannya di bidang administrasi dan dokumentasi yang bersifat harian, mingguan, maupun bulanan bahkan untuk mempersiapkan, membuat, menyusun, menyelesaikan laporan tahunan pun akan semakin mudah dan cepat.

2. Memberikan Hardcopy bahan materi dan Softcopy aplication microsoft office 2010 serta membantu menginsalnya bagi yang belum memiliki dilaptopnya.
3. Menjelaskan, memaparkan dan memperkenalkan cara memanfaatkan software application yang ada atau yang telah diinstal di dalam computer.

4. Software aplication yang tersedia atau yang terdapat di dalam komputer merupakan perangkat lunak siap pakai yang nantinya akan digunakan untuk membantu melaksanakan pekerjaan penggunanya. Dalam sebuah komputer aplikasi ini disiapkan sesuai kebutuhannya masing-masing.

5. Menjabarkan dan menjelaskan manfaat dan kegunaan dari Microsoft Office dalam tertib administrasi terutama dalam administrasi dokumentasi.

6. Menjelaskan dan memaparkan jenisjenis atau versi dari Microsoft Office yang telah familiar di kalangan pengguna aplikasi computer untuk administrasi dokumentasi seperti Microsoft Office 2003, Microsoft Office 2007, 2010, 2013, dan 2016.

7. Menjelaskan bagaimana membuat dokumentasi, surat, undangan dan table dari laporan yang selalu dibuat oleh pengurus organisasi Pembinaan Kesejahteraan Keluarga (PKK) akan jauh lebih mudah, cepat dan simple dengan menggunakan software aplikasi yang dikeluarkan oleh Microsoft ini 


\section{Jurnal Batoboh, Vol 5 , No 2, Oktober 2020}

Sunarsan Sitohang, Cecep Endang

yakni Microsoft word dibandingkan dengan cara lain seperti cara-cara yang selama ini digunakan oleh tim pengurus organisasi Pembinaan Kesejahteraan Keluarga (PKK) yaitu secara manual.

8. Menjelaskan dan memaparkan bagaimana manfaat dan kegunaan Microsoft Office Excel, membantu dalam kegiatan pembuatan laporan laporan keuangan PKK.

9. Menjelaskan dan memaparkan bagaimana manfaat dan kegunaan Microsoft Office PowerPoint, pembuatan persiapan presentasi hasil laporan PKK.

10. Memberikan pelatihan dasar pada para pengurus Pembinaan Kesejahteraan Keluarga (PKK) tentang penggunaan dan pemanfaatan Microsoft office 2010 yaitu Microsoft Word 2010, Microsoft Excel 2010 dan Microsoft PowerPoint 2010

11. Memberikan pendampingan pada para pengurus Pembinaan Kesejahteraan Keluarga (PKK) dalam penggunaan dan pemanfaatan Microsoft office 2010 yaitu Microsoft Word 2010, Microsoft Excel 2010 dan Microsoft Power Point 2010.

12. Melakukan pemantauan atau monitoring pada para pengurus Pembinaan Kesejahteraan Keluarga (PKK) terhadap kemampuan penguasaan mereka pada Microsoft Word 2010, Microsoft Excel 2010 dan Microsoft PowerPoint 2010 yang telah diajarkan dalam pelatihan dan pembinaan ini.

13. Melakukan evaluasi dan penilaian terhadap para pengurus Pembinaan Kesejahteraan Keluarga (PKK) yang mana mereka di waktu sebelumnya telah diberikan pengarahan, pemaparan, pelatihan, pendampingan serta pemantauan dalam peningkatan kemampuan mereka dalam penguasaan mereka terhadap software application Microsoft office 2010 seperti Microsoft Word 2010, Microsoft Excel 2010 dan Microsoft PowerPoint 2010 yang telah diajarkan dalam pelatihan dan pembinaan ini. 


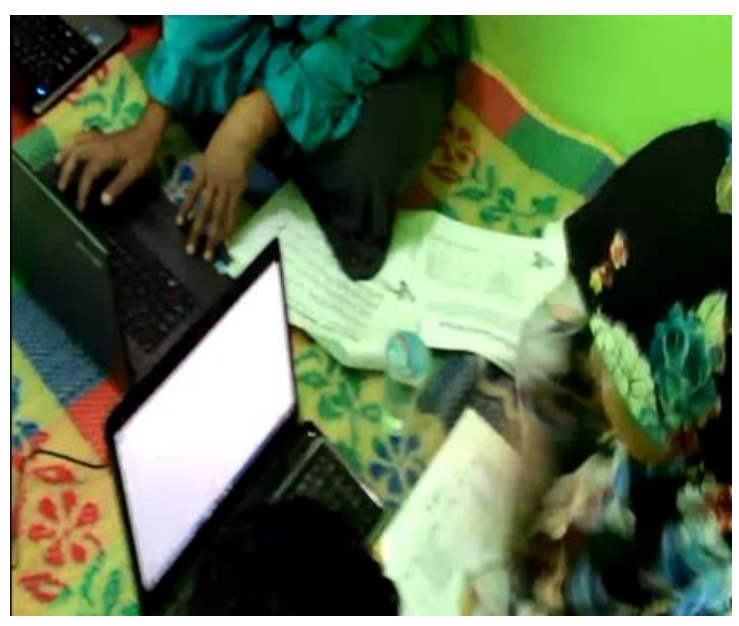

Gambar 1. Ibu PKK Praktek M.s Word

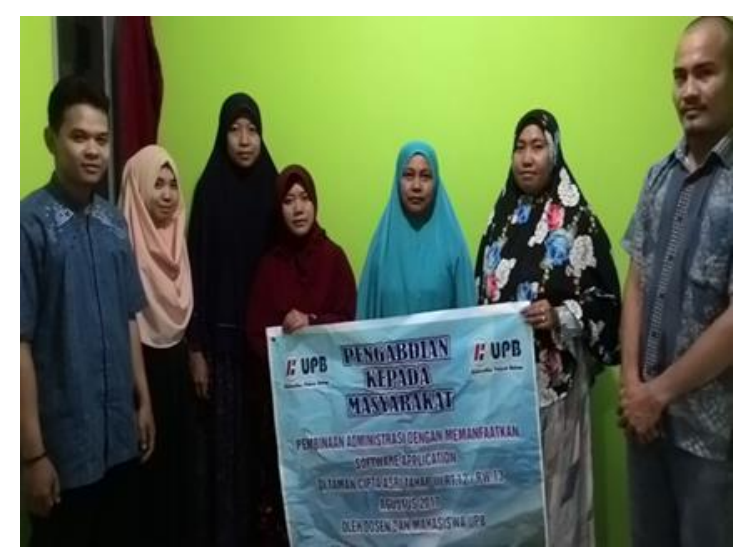

Gambar 2. Dokumentasi Hari Pertama

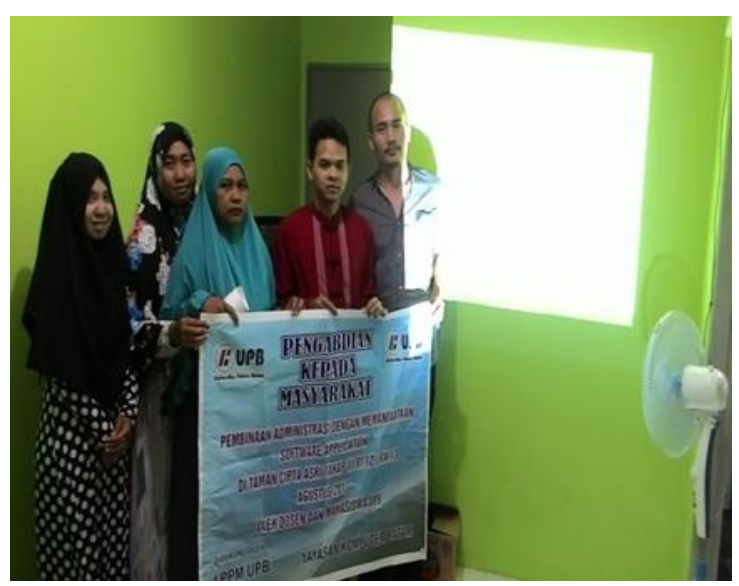

Gambar 3. Dokumentasi Hari Kedua

\section{SIMPULAN}

Dari kegiatan pengabdian yang dilakukan oleh tim pengabdi di lingkungan
RT 13, RW 12 Perumahan Taman Cipta Asri Tahap 3, Kelurahan Tembesi, Kecamatan Sagulung, Kotamadya Batam, Propinsi Kepulauan Riau disimpulkan sebagai berikut:

1. Memberikan pembinaan administrasi berbasis komputer dengan menggunakan software aplikasi khususnya microsoft office menjadikan ibu-ibu PKK di lingkungan RT 13, RW 12 Perumahan Taman Cipta Asri Tahap 3 lebih memahami dan mengerti fungsi microsoft office tersebut.

2. Ibu-ibu PKK di lingkungan RT 13, RW 12 Perumahan Taman Cipta Asri Tahap 3 lebih terlatih dengan menggunakan Software aplikasi khususnya Microsoft office.

3. Ibu-ibu PKK di lingkungan RT 13, RW 12 Perumahan Taman Cipta Asri Tahap 3 lebih mengerti dengan fitur-fitur dari Microsoft Word, Microsoft Exel dan Microsoft PowerPoint.

\section{KEPUSTAKAAN}

Basir, Muhammad Askal, Indra Gunawan, Wa Ode Nazila, and Ahmad Muhardin Hadmar. 2020. “Tata Kelola Administrasi Desa Dalam Pemanfaatan Sistem Aplikasi Komputer." Humanism : Jurnal 
Pengabdian Masyarakat 1(2):57-63.

Dhewy, Risdiana Chandra. 2018. “Pelatihan

Dasar-Dasar Statistika Dengan

Menggunakan Aplikasi Microsoft

Excel Di Sdn Pamotan Ii Kecamatan

Porong." Jurnal PADI - Pengabdian

MAsyarakat Dosen Indonesia 1(1):36-40.

Jarot S., Shenia A., Sudarma S. 2012. Buku

Pintar Microsoft Office 2007 \& 2010:

Word - Excel - PowerPoint. Pertama.

Jakarta selatan: Media Kita.

Richa Septima, and Ira Zulfa. 2020.

"Pelatihan Ilmu Teknologi Komputer

Dalam Meningkatkan Kemampuan

Administrasi Perangkat Desa Tan

Saril." JPKMI (Jurnal Pengabdian Kepada

Masyarakat Indonesia) 1(1):1-7.

Simanjuntak, Pastima, and Koko Handoko.

2019. “Pembinaan Administrasi Dan

Dokumentasi Dengan Memanfaatkan

Software Application." Jurdimas (Jurnal

Pengabdian Kepada Masyarakat) Royal

2(2):132-36. 